\title{
PERFIL PEDAGÓGICO/ADMINISTRATIVO DOS GESTORES ESCOLARES DO MUNICÍPIO DE RESERVA
}

\author{
EDUCACIONAL/ADMINISTRATIVE PROFILE \\ SCHOOL OF MANAGERS OF THE CITY OF RESERVA
}

\begin{abstract}
Antonio Mateus Bergamasco*
Rosilda de Moraes Bergamasco ${ }^{* *}$
\end{abstract}

\section{RESUMO}

Este estudo teve como objetivo analisar as práticas cotidianas dos diretores das escolas/colégios estaduais do município de Reserva, a fim de verificar se esses profissionais realizam atividades tanto de cunho administrativo quanto pedagógico, e com que frequência e de que forma elas são realizadas. Buscouse, também, verificar quais dessas atividades são prioridades para cada gestor. $\mathrm{Na}$ pesquisa foi utilizado o método survey, aplicando-se um questionário aos oito diretores da rede estadual do município. O questionário contemplou dados referentes aos aspectos administrativos e pedagógicos que envolvem a gestão escolar. A pesquisa revelou que os diretores pesquisados costumam realizar atividades tanto referentes à gestão administrativa quanto pedagógica, no entanto algumas tarefas de cunho pedagógico ainda precisam ser mais frequentemente realizadas, bem como é fundamental que os diretores se considerem como um dos principais agentes responsáveis pela aprendizagem. Só assim conseguirão promover um equilíbrio entre os aspectos administrativos e pedagógicos e, consequentemente, poderão se considerar realmente gestores escolares e não meros administradores de escola.

Palavras-chave: Administração escolar. Gestão escolar. Perfil do gestor escolar. Atividades administrativas e pedagógicas.

\begin{abstract}
This study analyzed the daily practices of elementary and high school directors to see whether these professionals teach as well carry out administrative activities, how often and how they are performed. This research also sought to determine which of these activities represent a priority for each manager. The research used a survey method which included the application of a questionnaire to eight directors of mainstream schools of the municipality. The questionnaire contained
\end{abstract}

\footnotetext{
* Graduação em Geografia - UEPG, especializações em Geografia: organização do espaço e meio ambiente - FAFIJAN e Educação, Gestão Escolar, Supervisão de Ensino, Orientação Educacional e Administração - Faculdade Iguaçu.

** Graduação em Letras - UEPG, especialização em Educação, Gestão Escolar, Supervisão de Ensino, Orientação Educacional e Administração - Faculdade Iguaçu e Mestrado em Letras - UEM.
} 
data concerning both administrative and teaching aspects of school management. The study demonstrated that the directors surveyed conduct both administrative and pedagogical activities, however some educational tasks need to be performed more often, and it is essential that the directors consider themselves as one of the main actors responsible for learning. Once they develop this understanding, they will be able to promote a balance between administrative and teaching tasks and, consequently, they will consider themselves more than mere school managers.

Keywords: School administration. School management. School manager profile. Pedagogical and administrative activities.

\section{Introdução}

O conceito de Gestão Escolar é relativamente recente no Brasil, passou a ser utilizado a partir da Constituição Federal de 1988, quando se institucionalizou a gestão democrática do ensino público. Até então, a Gestão Escolar era nomeada de Administração Escolar. Essa mudança de nomenclatura não se deu apenas na escrita, ela contempla também uma nova forma de conceber teoricamente essa atividade, ou seja, o diretor escolar ganha um novo perfil. Tal perfil não está mais ligado apenas aos aspectos administrativos de um estabelecimento de ensino, a gestão administrativa é somente uma das responsabilidades do diretor. Ele também é responsável pela gestão pedagógica e pela gestão de recursos humanos, que devem ser realizadas de forma integrada, sistêmica no seu cotidiano de trabalho.

Diante dessa nova configuração do papel do gestor escolar, ele se torna uma peça fundamental na dinamização e sucesso do ensino e da aprendizagem dos alunos. Nesse sentido, o presente artigo objetiva investigar se os diretores escolares têm incorporado nas suas atividades cotidianas esse novo perfil de gestor escolar, isto é, se têm realizado as atividades tanto de cunho administrativo quanto pedagógico, ou se ainda continuam presos à antiga noção de meros administradores.

Para tanto, este texto enfocará a importância do gestor escolar no que se refere à aprendizagem dos educandos, bem como apresentará os resultados da pesquisa de campo realizada com diretores escolares do município de Reserva.

\section{Administração escolar X gestão escolar}

O cargo de diretor de escola foi criado a partir da aprovação e aplicação da Lei n ${ }^{0}$ 5.691/71, quando os cursos primário e ginasial passaram a constituir um único curso - o ensino de primeiro grau - com duração de oito anos e de caráter obrigatório. Até então, existia o diretor de grupo escolar. Além da mudança de nomenclatura, a imagem de diretor se tornou equivalente a de um administrador, com a exigência de qualificações mais específicas para o cargo, como se nota nas palavras de Antunes (2008, p. 8):

A concepção de administração escolar que predominou durante todo este período apoiou-se no modelo clássico da administração empresarial. Ou seja, a administração era concebida como um processo técnico, cientificamente determinado e burocrático, cujo fim era obter unidade, economia de tempo e de recursos e maior produtividade. Esse processo envolvia normas rígidas, autoridade centralizada, hierarquia, planejamento, organização detalhada e avaliação de resultados.

No fim da década de 70 e início da década de 80 , no entanto, as lutas sociais em favor da democracia se fortalecem e esse desejo atinge também o campo da educação. Assim, surgem manifestações em defesa da criação de eleições diretas para os dirigentes das instituições de ensino, bem como a criação dos colegiados escolares, escolhidos pela comunidade, com a finalidade de democratizar a gestão escolar. Essas propostas acabam sendo contempladas na Constituição Federal promulgada em 1988, a qual estabelece no inciso VI, do artigo 206, a garantia da gestão democrática no ensino público. Com a aprovação da Lei $n^{0} 9.394$, em 1996, a Lei de Diretrizes e Bases da Educação Nacional, o 
estabelecimento da gestão democrática no sistema educacional também é confirmado.

Essa forma de gestão vinha sendo defendida como uma dinâmica a ser efetivada dentro do contexto escolar, de forma a garantir processos coletivos de participação e decisão. No entanto, ela

[...] requer mais do que simples mudanças nas estruturas organizacionais; requer mudança de paradigmas que fundamentem a construção de uma proposta educacional e o desenvolvimento de uma gestão diferente da que hoje é vivenciada. Ela precisa estar para além dos padrões vigentes, comumente desenvolvidos pelas organizações burocráticas. (BORDIGNON e GRACINDO, 2004, p. 147).

Desse modo, a partir dos anos 90, o diretor não é mais visto como administrador e sim como gestor. Com a alteração na forma de conceituar esse cargo, modifica-se também a concepção de gestão, que, de acordo com Antunes (2008, p. 9), "passa a ser sinônimo de ambiente autônomo e participativo, o que implica trabalho coletivo e compartilhado por várias pessoas para atingir objetivos comuns". Nesse sentido, o objetivo da gestão escolar é organizar, mobilizar e articular todos os recursos necessários para que o processo de ensino e aprendizagem se efetive da melhor forma possível dentro do estabelecimento de ensino, com a finalidade de promover a aprendizagem dos alunos. Com isso, o papel do diretor também se redefine, ou seja, o diretor deixa de ser a pessoa que fiscaliza, controla e centraliza em si todas as decisões e se torna a pessoa que

[...] coordena, mobiliza, motiva, lidera, delega aos membros da equipe escolar, conforme suas atribuições específicas, as responsabilidades decorrentes das decisões, acompanha o desenvolvimento das ações, presta contas e submete à avaliação da equipe o desenvolvimento das decisões tomadas coletivamente (LIBÂNIO; OLIVEIRA; TOSCHI, 2003, p. 335).

Assim, as decisões a serem tomadas dentro do contexto escolar não estão mais nas mãos de apenas uma pessoa, do diretor, elas devem ser planejadas e realizadas coletivamente, de forma a integrar todos os agentes envolvidos na escola - diretores, professores, funcionários administrativos e serviços gerais, pedagogos, pais, alunos e comunidade. Ressalta-se, através disso, o papel da equipe gestora como participante ativa e responsável pelo desenvolvimento do trabalho escolar. Mas, para que essa equipe gestora seja atuante dentro da escola, é fundamental o papel do gestor:

Para que haja a participação efetiva dos membros da comunidade escolar, é necessário que o gestor, em parceria com o conselho escolar, crie um ambiente propício que estimule trabalhos conjuntos, que considere igualmente todos os setores, coordenando os esforços de funcionários, professores, pessoal técnico-pedagógico, alunos e pais envolvidos no processo educacional. (OLIVEIRA; MORAES; DOURADO, 2010, p. 5).

Percebe-se, desse modo, que a mudança de nomenclatura, de administrador para gestor, implica necessariamente uma mudança de conceito. Se até então o modelo de administração escolar era pautado na burocracia e no autoritarismo, a partir desse momento esse modelo deve ser alterado, dando lugar ao modelo de gestão escolar. Um modelo que procura superar o enfoque limitado do conceito de administração escolar, partindo do entendimento de que os problemas educacionais são complexos e por essa razão demandam uma ação articulada e conjunta, com o objetivo de superar os problemas que surgem no cotidiano escolar.

O conceito de gestão escolar, nesse sentido,

está associado à mobilização de talentos e esforços coletivamente organizados, à ação construtiva conjunta de seus componentes, pelo trabalho associado, mediante reciprocidade que cria um 'todo' orientado por uma vontade coletiva. (LÜCK, 2005, p. 17).

Considerando o caráter coletivo, conjunto que a gestão escolar pressupõe, é natural que se considere como um dos seus princípios a gestão democrática, a qual se caracteriza pelo trabalho coletivo, participativo e dialógico. De acordo com Ferreira (2006, p. 310), a gestão democrática se concretiza, de fato, quando

[...] se tomam decisões sobre todo o projeto político pedagógico, sobre as finalidades e objetivos do planejamento dos cursos, das disciplinas, dos planos de estudos, do elenco disciplinar e os respectivos conteúdos, sobre as atividades dos professores e dos alunos necessárias para a sua consecução, sobre os ambientes de aprendizagem, recursos humanos, físicos e financeiros necessários, os tipos, modos e procedimentos de avaliação e o tempo para sua realização. É quando se organiza e se administra coletivamente todo esse processo [...]. 
Portanto, dentro da gestão escolar três áreas devem funcionar interligadas, de forma integrada, sistêmica: a gestão pedagógica, a gestão de recursos humanos e a gestão administrativa. As especificidades dessas três dimensões da gestão escolar estão explicitadas no Regimento Escolar, no Projeto Político-Pedagógico e no Plano de Ação da equipe gestora de cada escola. A gestão administrativa se refere ao cuidado com a parte física e institucional do estabelecimento de ensino. A gestão de recursos humanos diz respeito à gestão de pessoal, ou seja, de alunos, professores, funcionários, pais e comunidade. A gestão pedagógica, por sua vez, pode ser considerada a área mais importante e significativa da gestão escolar, uma vez que é responsável por cuidar mais diretamente da área educativa. Por isso, a gestão pedagógica agrega funções como as de:

- estabelecer objetivos para o ensino;

- definir as linhas de atuação, em função dos objetivos e do perfil da comunidade e dos alunos;

- propor metas a serem atingidas;

- acompanhar e avaliar o rendimento das propostas pedagógicas, dos objetivos e o cumprimento de metas e;

- avaliar o desempenho dos alunos, do corpo docente e da equipe escolar como um todo.

O diretor, dentro dessa perspectiva, é o principal articulador e responsável pelo sucesso da gestão pedagógica, mas não está sozinho nessa tarefa, pois toda a sua equipe gestora tem a função de auxiliá-lo. Considerando todas as dimensões que fazem parte da gestão escolar, percebe-se que o diretor de escola, como bem afirma Antunes (2008, p. 3), "tem uma importância fundamental na organização e funcionamento da instituição escolar, em todos os seus aspectos: físico, sócio-político, relacional, material, financeiro e pedagógico.” (ANTUNES, 2008, p. 3) Assim, não se justifica que o diretor apenas tome para si a responsabilidade de supervisionar ou realizar atividades administrativas, pois estas se referem somente a um dos aspectos da gestão escolar, como podemos perceber nas palavras de Nascimento (2005, p. 166):

Portanto, há que se definir com maior precisão o conceito de gestão escolar, da forma como a entendemos no Brasil, buscando explicitar melhor sua natureza e as adjetivações a ela subjacentes, como democrática e participativa, por exemplo. É evidente que a gestão escolar transcende em muito a dimensão administrativa, assumindo, também, dimensão pedagógica, constituindo-se em elemento de mediação de processos que permeiam a instituição escolar, envolvendo meios e fins.

Percebe-se, assim, que o perfil do diretor escolar deve se adequar a essa nova forma de conceber a sua função, de modo a incorporar no seu trabalho as características inerentes ao conceito de gestão. De acordo com Libâneo (2004, p. 217), diretores com esse novo perfil já são mais comuns do que aqueles que ainda concebem o cargo de diretor associado ao de administrador:

Muitos dirigentes escolares foram alvos de críticas por práticas excessivamente burocráticas, conservadoras, autoritárias, centralizadoras. Embora aqui e ali continuem existindo profissionais com esse perfil, hoje estão disseminadas práticas de gestão participativa, liderança participativa, atitudes flexíveis e compromisso com as necessárias mudanças na educação. (LIBÂNEO, 2004, p. 217).

No entanto, em muitas escolas ainda predomina a concepção de diretor como administrador e por isso apenas as funções administrativas, burocráticas acabam sendo atribuídas à direção, como observa Alonso (2004, p. 3):

É muito comum os gestores dividirem entre si as tarefas de acompanhamento pedagógico, ficando para os coordenadores a responsabilidade de analisar com os professores as dificuldades encontradas nesse percurso e ajudá-los a encontrar soluções para sanar os problemas. Embora essa seja uma prática comum nas escolas de ensino fundamental, observa-se que ela reforça o caráter individualista da atividade docente ao invés de abrir espaço para uma ação coletiva que possibilitaria trazer para a discussão outros problemas comuns a vários professores, os quais nem sempre são encorajados a fazê-lo. A par disso, nota-se que esse procedimento aparentemente adequado revela o outro lado da questão que reforça a tendência de separar o administrativo do pedagógico, na medida em que libera o corpo diretivo de qualquer envolvimento com o trabalho docente. Esse encaminhamento da questão poderia suscitar dúvidas frente às inúmeras demandas que se apresentam ao diretor exigindo dele atenção, algumas vezes em caráter de urgência. 
Ainda de acordo com Alonso (2004, p. 2), a divisão de tarefas administrativas e pedagógicas não pode acontecer, pois as duas atividades só fazem sentido se forem realizadas de forma articulada, com a finalidade de otimizar o processo de ensino e aprendizagem. Além disso, o diretor não pode se eximir da responsabilidade de ser o principal responsável pelo sucesso da aprendizagem dos alunos.

Portanto, nunca é demais advertir que o trabalho de gestão não comporta separação das tarefas administrativas e pedagógicas nos moldes em que costuma ocorrer. Mesmo porque, o trabalho administrativo somente ganha sentido a partir das atividades pedagógicas que constituem as atividades-fim, ou propósitos da organização escolar. Assim vista a questão, torna-se inaceitável a divisão, muito freqüente, de atribuições em que o diretor responde pelo trabalho administrativo rotineiro, burocrático e de representação, sem qualquer compromisso com o trabalho pedagógico, visto como responsabilidade exclusiva dos professores e especialistas do ensino.

Nesse sentido, é papel do gestor conseguir equilibrar todos os aspectos da gestão escolar, como afirma Silva (2009, p. 70):

$\mathrm{O}$ gestor educacional tem assim, uma árdua tarefa de buscar o equilíbrio entre os aspectos pedagógicos e administrativos, com a percepção que o primeiro constitui-se como essencial e deve privilegiar a qualidade, por interferir diretamente no resultado da formação dos alunos, e o segundo deve dar condições necessárias para o desenvolvimento pedagógico.

E, acima de tudo, as suas decisões administrativas devem se pautar nos objetivos que pretende alcançar para que as questões pedagógicas sejam contempladas, como conclui Alonso (2004, p. 5) sobre o papel do diretor em relação ao ensino e a aprendizagem escolar:

Portanto, é fundamental que o diretor perceba o seu papel e as suas funções a partir dos objetivos educacionais e dos projetos que a escola se propõe a desenvolver. O que não se pode conceber é uma administração que define prioridades com base em critérios internos da própria função, permitindo uma expansão desmedida desse setor em detrimento das atividades-fim da escola, quais sejam: o ensino e a aprendizagem.
Afinal, o diretor, enquanto maior responsável pela efetivação do processo de ensino e aprendizagem dentro do ambiente escolar, precisa contribuir de forma direta e efetiva para que os professores tenham condições adequadas, favoráveis às práticas educativas desenvolvidas dentro de sala de aula. Nesse aspecto, o gestor é de fundamental importância, já que pode agir como um elemento facilitador, ou obstaculizador, do trabalho pedagógico:

Enquanto responsável último pelo desempenho escolar compete ao dirigente prover as condições necessárias para que o trabalho pedagógico possa desenvolver-se da melhor forma possível e de acordo com a Proposta Pedagógica estabelecida em conjunto com a comunidade escolar. Ao tempo que se espera do diretor uma ação provedora das condições e facilitadora desse trabalho, é de se supor que ele desenvolva instrumentos adequados de acompanhamento e orientação das atividades pedagógicas, permitindo a ele e aos demais educadores o controle dessas ações segundo critérios claramente estabelecidos com os professores e demais membros da comunidade escolar. (ALONSO, 2004, p. 6).

Além disso, é papel do diretor não só oferecer condições adequadas de trabalho com as práticas pedagógicas, como também é seu dever acompanhar e orientar o trabalho pedagógico, como nos relata Alonso (2004, p. 8):

Ao mesmo tempo em que se espera do diretor uma ação provedora das condições e facilitadora desse trabalho, é de se supor que ele desenvolva instrumentos adequados de acompanhamento e orientação das atividades pedagógicas, permitindo-lhe o controle dessas ações segundo critérios claramente estabelecidos com os professores e demais membros da comunidade escolar.

Portanto, as funções de um diretor escolar vão além das atividades meramente administrativas, burocráticas; elas devem ser realizadas em consonância com as funções de cunho pedagógico, pois só assim terão sentido dentro do contexto escolar. Pode-se concluir que as funções pedagógicas não só são de competência do diretor, como devem ser a prioridade do gestor, já que não se pode mais concebê-lo apenas como um mero administrador. Afinal, o conceito de gestão vigente atualmente encerra um significado muito mais abrangente do que o da administração escolar. 


\section{Metodologia}

O objetivo desta pesquisa é verificar se os diretores das escolas/colégios estaduais do município de Reserva, estado do Paraná, conseguem articular satisfatoriamente as atividades de cunho administrativo e de cunho pedagógico, ou se apenas uma das atividades é priorizada. Sendo assim, foi desenvolvida uma pesquisa descritiva do tipo survey, que é aquela que, de acordo com Lima (2004, apud TERRIBILI, 2007, p. 62), "visa a determinar quais situações, eventos, atitudes ou opiniões estão manifestos em uma determinada população". Ainda de acordo com Lima (2004, p. 26),

O método de pesquisa survey é, atualmente, o que melhor representa as características da pesquisa quantitativa, e isto porque corresponde a uma abordagem do fenômeno investigado envolvendo a realização de uma pesquisa de campo, na qual a coleta de dados é feita por meio de aplicação de questionário e/ou formulário junto à população-alvo da pesquisa.

A população participante da pesquisa foi composta por todos os diretores de escolas e de colégios estaduais, do ensino fundamental e médio do município de Reserva, no ano de 2011, totalizando assim oito profissionais que responderam voluntariamente ao questionário da pesquisa. Foi utilizado um questionário que tinha em sua composição perguntas fechadas, de múltipla escolha. Esse questionário resultou da adaptação de parte de um questionário maior elaborado pela Fundação Victor Civita para a realização de uma pesquisa, em 2009, com diretores de escolas municipais e estaduais de algumas capitais do Brasil, com a finalidade de traçar o perfil desses profissionais ${ }^{1}$.

A parte do questionário adaptada para esta pesquisa versa sobre as práticas cotidianas dos diretores e a frequência com que eles realizam atividades de cunho pedagógico e administrativo, bem como se questiona também sobre quais atividades - administrativas ou pedagógicas - são priorizadas durante a sua gestão. Além disso, os diretores devem opinar sobre quem seriam os maiores responsáveis pela aprendizagem dos alunos na escola.
O questionário aplicado aos diretores continha três questões. A primeira era a seguinte: "Diretor(a), poderia dizer com que frequência você realiza cada uma das atividades enumeradas a seguir, se realiza a atividade todo dia, uma ou algumas vezes por semana, uma ou algumas vezes por mês, uma ou algumas vezes por semestre, uma ou algumas vezes por ano, ou não realiza? E na sua opinião, o(a) $\operatorname{Sr}(a)$ diria que essa frequência com que realiza cada atividade é 'Insuficiente', 'Adequada', ou 'Excessiva'?'

$\mathrm{Na}$ sequência dessa pergunta foi inserida uma planilha com dezenove atividades que fazem parte da rotina de um diretor, subdivididas em quatro blocos: $1^{\circ}$ bloco - atividades sobre a gestão da aprendizagem (cinco atividades); $2^{\circ}$ bloco - atividades sobre infraestrutura e material pedagógico (cinco atividades); $3^{\circ}$ bloco - atividades sobre a organização da sala e produção dos alunos (três atividades) e $4^{\mathrm{o}}$ bloco - atividades sobre a interação com a comunidade (seis atividades).

A segunda questão era esta: "Numa escala de 1 a 10 , onde 1 representa 'menor prioridade' e 10 representa 'maior prioridade', qual o nível de prioridade que você atribui para cada uma das atividades abaixo realizadas por você em sua gestão?”.

Após essa pergunta foi colocada uma planilha contendo duas atividades: administrativas/burocráticas e pedagógicas de sala de aula e números de 1 a 10, para que fossem enumeradas de acordo com o nível de prioridade para sua realização dentro do cotidiano escolar.

A terceira questão do questionário era a seguinte: "Desses seis agentes indicados abaixo, na sua opinião, qual é o principal responsável pela aprendizagem? E o segundo? Qual o terceiro?”.

Abaixo da pergunta havia uma planilha com seis agentes (professor, direção, coordenação pedagógica, família, governo, alunos) e um espaço para que se escolhessem os três principais agentes responsáveis pela aprendizagem escolar.

Com a finalidade de coletar esses dados, os pesquisadores entraram em contato com os oito diretores das escolas/colégios estaduais para verificar a possibilidade de sua participação na pesquisa. Após o consentimento de todos, foi aplicado o questionário e, após uma semana, recolhido. Para análise dos

\footnotetext{
${ }^{1}$ O questionário utilizado pela Fundação Victor Civita está disponível no site: <www.fvc.org.br/fvc/pdf/coordenador-questionario.pdf > .
} 
dados resultantes da aplicação do questionário foi utilizado um procedimento da estatística descritiva, ou seja, através da média, porcentagem, de forma a verificar a frequência com que os dados ocorrem. Para uma melhor visualização, os resultados foram dispostos em tabelas e gráficos.

\section{Resultados e discussão}

O primeiro bloco de perguntas do questionário aplicado solicitava que os diretores informassem a frequência e o modo como as atividades referentes à gestão de aprendizagem são realizadas durante a gestão, conforme mostra o quadro a seguir.

Quadro 1 - Gestão de aprendizagem

\begin{tabular}{|c|c|c|c|c|c|c|c|c|c|c|c|}
\hline & & & Todo dia & $\begin{array}{c}\text { Uma ou } \\
\text { algumas } \\
\text { vezes por } \\
\text { semana }\end{array}$ & $\begin{array}{c}\text { Uma ou } \\
\text { algumas } \\
\text { vezes por } \\
\text { mês }\end{array}$ & $\begin{array}{c}\text { Uma ou } \\
\text { algumas } \\
\text { vezes por } \\
\text { semestre }\end{array}$ & $\begin{array}{c}\text { Uma ou } \\
\text { algumas } \\
\text { vezes por } \\
\text { ano }\end{array}$ & Não faz & Insuficiente & Adequada & Excessiva \\
\hline \multirow{2}{*}{1} & \multirow{2}{*}{$\begin{array}{c}\text { Acompanha e } \\
\text { participa das } \\
\text { reuniões periódicas } \\
\text { dos professores } \\
\text { com a equipe } \\
\text { pedagógica? }\end{array}$} & $\%$ & 25 & 12,5 & 25 & 37,5 & & & 12,5 & 87,5 & \\
\hline & & $\begin{array}{c}\text { Número de } \\
\text { diretores }\end{array}$ & 2 & 1 & 2 & 3 & & & 1 & 7 & \\
\hline \multirow{2}{*}{2} & \multirow{2}{*}{$\begin{array}{c}\text { Faz reuniões } \\
\text { com a equipe } \\
\text { pedagógica para } \\
\text { discutir o ensino } \\
\text { e a aprendizagem } \\
\text { de alunos e } \\
\text { professores? }\end{array}$} & $\%$ & 12,5 & 37,5 & 12,5 & 25 & 12,5 & & 12,5 & 87,5 & \\
\hline & & $\begin{array}{c}\text { Número de } \\
\text { diretores }\end{array}$ & 1 & 3 & 1 & 2 & 1 & & 1 & 7 & \\
\hline \multirow[b]{2}{*}{3} & \multirow{2}{*}{$\begin{array}{c}\text { Analisa com } \\
\text { regularidade } \\
\text { as planilhas de } \\
\text { acompanha-mento } \\
\text { da aprendizagem } \\
\text { dos alunos? } \\
\end{array}$} & $\%$ & 12,5 & & 37,5 & 25 & 12,5 & 12,5 & 50 & 50 & \\
\hline & & \begin{tabular}{|c|} 
Número de \\
diretores
\end{tabular} & 1 & & 3 & 2 & 1 & 1 & 4 & 4 & \\
\hline \multirow{2}{*}{4} & \multirow{2}{*}{$\begin{array}{l}\text { Oferece na escola } \\
\text { atividades para } \\
\text { apoio aos alunos } \\
\text { com dificuldades? }\end{array}$} & $\%$ & 37,5 & 50 & 12,5 & & & & 12,5 & 87,5 & \\
\hline & & \begin{tabular}{|c}
$\begin{array}{c}\text { Número de } \\
\text { diretores }\end{array}$ \\
\end{tabular} & 3 & 4 & 1 & & & & 1 & 7 & \\
\hline \multirow{2}{*}{\multicolumn{2}{|c|}{$5 \mid \begin{array}{c}\text { Verifica periodica- } \\
\text { mente a frequência } \\
\text { de estudantes, } \\
\text { professores e fun- } \\
\text { cionários? }\end{array}$}} & $\%$ & 87,5 & & 12,5 & & & & & 87,5 & 12,5 \\
\hline & & $\begin{array}{c}\text { Número de } \\
\text { diretores }\end{array}$ & 7 & & 1 & & & & & 7 & 1 \\
\hline
\end{tabular}

Fonte: Pesquisa de campo.

No que se refere ao acompanhamento e participação em reuniões com professores e equipe pedagógica, o resultado foi bem diverso: $37,5 \%$ dos entrevistados realizam essa atividade uma ou algumas vezes por semestre; $25 \%$ realizam todo dia, ou uma ou algumas vezes por mês; e 12,5 realizam uma ou algumas vezes por mês, sendo que $87,5 \%$ dos diretores questionados consideram a frequência adequada e apenas $12,5 \%$ a avaliam como insuficiente.

Em relação à realização de reuniões com a equipe pedagógica para discutir o ensino e a aprendizagem dos professores e alunos, a frequência também foi bem variada, sendo que $37,5 \%$ dos diretores as realizam uma ou algumas vezes por semana; $25 \%$ realizam uma ou algumas vezes por semestre; $12,5 \%$ realizam todo dia; outros $12,5 \%$ realizam uma ou algumas vezes por mês; e outros 12,5 realizam uma ou algumas vezes por ano. Assim como na questão anterior, $87,5 \%$ dos diretores questionados consideram a frequência adequada e apenas 12,5 a classificam como insuficiente. 
Sobre a regularidade com que o diretor analisa as planilhas de acompanhamento da aprendizagem dos alunos, a maior parte dos diretores realiza essa atividade com uma frequência menor, sendo que $37,5 \%$ deles analisam essas planilhas uma ou algumas vezes por mês; $25 \%$ analisam uma ou algumas vezes por semestre; $12,5 \%$ analisam uma ou algumas vezes por ano; $12,5 \%$ analisam todo dia; e 12,5 revelaram que não realizam essa atividade. No que se refere ao modo como essa atividade é realizada, observa-se que a metade $(50 \%)$ dos diretores entrevistados considera adequada essa freqüência, enquanto que os outros $50 \%$ a julgam insuficiente.

Ao serem questionados se a escola oferece atividades para apoio aos alunos com dificuldades de aprendizagem, notou-se que todos os diretores procuram oferecer essas atividades com uma alta frequência, sendo que $50 \%$ dos entrevistados as oferecem uma ou algumas vezes por semana; $37,5 \%$ oferecem todo dia; e 12,5 oferecem uma ou algumas vezes por mês. Em relação ao modo como essas atividades são oferecidas, $87,5 \%$ dos diretores o consideram como adequado e apenas $12,5 \%$ como insuficiente.

Os resultados da questão "Verifica periodicamente a frequência de estudantes, professores e funcionários?" mostraram que $87,5 \%$ dos entrevistados realizam essa atividade todos os dias e 12,5 realizam uma ou algumas vezes por mês, sendo que $87,5 \%$ consideram adequada essa frequência e $12,5 \%$ rotulam como excessivo o tempo que gastam realizando tal atividade.

De acordo com os resultados obtidos nesse quadro, nota-se que a maior parte dos diretores, apesar de realizar as atividades com uma frequência bem variada, considera adequada a sua prática. Apenas sobre a análise das planilhas de acompanhamento da aprendizagem dos alunos é que se percebe que os diretores não realizam essa atividade frequentemente e, por isso, a metade dos entrevistados considera insuficiente essa prática. Vale ressaltar, também, que nas questões sobre o oferecimento de atividades de apoio aos alunos com dificuldade e sobre a verificação da frequência dos estudantes, professores e funcionários, ficou evidente que os diretores realizam essas atividades frequentemente e, assim, a maior parte dos entrevistados as considera adequadas.

O segundo bloco de perguntas diz respeito à realização das atividades relacionadas à infraestrutura e material pedagógico, como se pode ver no quadro apresentado a seguir.

Quadro 2 - Infraestrutura e material pedagógico

\begin{tabular}{|c|c|c|c|c|c|c|c|c|c|c|c|}
\hline & & & Todo dia & $\begin{array}{c}\text { Uma ou } \\
\text { algumas } \\
\text { vezes por } \\
\text { semana }\end{array}$ & $\begin{array}{c}\text { Uma ou } \\
\text { algumas } \\
\text { vezes por } \\
\text { mês }\end{array}$ & $\begin{array}{c}\text { Uma ou } \\
\text { algumas } \\
\text { vezes por } \\
\text { semestre }\end{array}$ & $\begin{array}{c}\text { Uma ou } \\
\text { algumas } \\
\text { vezes por } \\
\text { ano }\end{array}$ & Não faz & Insuficiente & Adequada & Excessiva \\
\hline \multirow{2}{*}{6} & \multirow{2}{*}{$\begin{array}{c}\text { Fornece os } \\
\text { materiais } \\
\text { necessários para } \\
\text { o desenvolvi- } \\
\text { mento das } \\
\text { atividades } \\
\text { pedagógicas } \\
\text { escolares? }\end{array}$} & $\%$ & 100 & & & & & & & 87,5 & 12,5 \\
\hline & & $\begin{array}{c}\text { Número de } \\
\text { diretores }\end{array}$ & 8 & & & & & & & 7 & 1 \\
\hline \multirow{2}{*}{7} & \multirow{2}{*}{$\begin{array}{c}\text { Assegura que } \\
\text { todas as salas te- } \\
\text { nham mobiliário } \\
\text { suficiente e em } \\
\text { boas condições } \\
\text { de uso? }\end{array}$} & $\%$ & 87,5 & 12,5 & & & & & & 87,5 & 12,5 \\
\hline & & $\begin{array}{c}\text { Número de } \\
\text { diretores }\end{array}$ & 7 & 1 & & & & & & 7 & 1 \\
\hline \multirow{2}{*}{8} & \multirow{2}{*}{$\begin{array}{c}\text { Providencia espa- } \\
\text { ço, na escola e na } \\
\text { sala de aula, para } \\
\text { a divulgação das } \\
\text { produções dos } \\
\text { alunos? }\end{array}$} & $\%$ & 50 & 37,5 & & & & 12,5 & 12,5 & 75 & 12,5 \\
\hline & & $\begin{array}{c}\text { Número de } \\
\text { diretores }\end{array}$ & 4 & 3 & & & & 1 & 1 & 6 & 1 \\
\hline
\end{tabular}




\begin{tabular}{|c|c|c|c|c|c|c|c|c|c|c|c|}
\hline & & & Todo dia & $\begin{array}{c}\text { Uma ou } \\
\text { algumas } \\
\text { vezes por } \\
\text { semana }\end{array}$ & $\begin{array}{c}\text { Uma ou } \\
\text { algumas } \\
\text { vezes por } \\
\text { mês }\end{array}$ & $\begin{array}{c}\text { Uma ou } \\
\text { algumas } \\
\text { vezes por } \\
\text { semestre }\end{array}$ & $\begin{array}{c}\text { Uma ou } \\
\text { algumas } \\
\text { vezes por } \\
\text { ano }\end{array}$ & Não faz & Insuficiente & Adequada & Excessiva \\
\hline \multirow{2}{*}{9} & \multirow{2}{*}{$\begin{array}{c}\text { Investe no acervo } \\
\text { da biblioteca, } \\
\text { cuidando da } \\
\text { qualidade lite- } \\
\text { rária dos livros } \\
\text { adquiridos? }\end{array}$} & $\%$ & 37,5 & 12,5 & & 25 & 25 & & 50 & 37,5 & 12,5 \\
\hline & & $\begin{array}{c}\text { Número de } \\
\text { diretores }\end{array}$ & 3 & 1 & & 2 & 2 & & 4 & 3 & 1 \\
\hline \multirow{2}{*}{10} & \multirow{2}{*}{$\begin{array}{l}\text { Assegura uma } \\
\text { merenda de } \\
\text { qualidade todos } \\
\text { os dias? }\end{array}$} & $\%$ & 100 & & & & & & & 75 & 25 \\
\hline & & $\begin{array}{c}\text { Número de } \\
\text { diretores }\end{array}$ & 8 & & & & & & & 6 & 2 \\
\hline
\end{tabular}

Fonte: Pesquisa de campo.

Em relação ao fornecimento de materiais necessários ao desenvolvimento das atividades pedagógicas escolares, verificou-se que todos os diretores entrevistados $(100 \%)$ procuram realizar essa atividade todos os dias, de modo que a maioria $(87,5 \%)$ considera adequada a frequência com que essa atividade é realizada e $12,5 \%$ a julgam excessiva. Quanto à segunda questão desse bloco, nota-se que o resultado obtido é idêntico.

Ao analisarmos a terceira questão: "Providencia espaço, na escola e na sala de aula, para a divulgação das produções dos alunos?", verifica-se que a metade dos entrevistados $(50 \%)$ realiza essa atividade todos os dias; $37,5 \%$ a realizam uma ou algumas vezes por semana, enquanto que $12,5 \%$ não realizam essa atividade, ou seja, não providenciam espaço na escola e na sala de aula para a divulgação das produções dos alunos, o que significa que esse percentual de diretores não procura valorizar o que os alunos estão aprendendo em sala de aula. Observou-se, também, que $75 \%$ dos diretores consideram adequada a frequência com que providenciam esse espaço, $12,5 \%$ a classificam como excessiva e $12,5 \%$ a julgam insuficiente.

Por outro lado, no que se refere ao investimento feito pelo diretor no acervo da biblioteca e no zelo com a qualidade literária dos livros adquiridos, verificou-se que a regularidade com que essa atividade é realizada ainda é baixa, sendo que $37,5 \%$ dos entrevistados investem todos os dias; $12,5 \%$ uma ou algumas vezes por semana; $25 \%$ investem uma ou algumas vezes por semestre; e outros $25 \%$ investem uma ou algumas vezes por ano. Diante da baixa frequência com que essa atividade é feita, notou-se que apenas $37,5 \%$ dos diretores a consideram adequada, enquanto que a metade dos entrevistados (50\%) a rotula como insuficiente e $12,5 \%$ a avaliam como excessiva.

Já em relação a assegurar uma merenda de qualidade para os alunos todos os dias, foi possível constatar que a resposta de todos os diretores $(100 \%)$ a essa questão foi afirmativa. Esse resultado demonstra que a preocupação com a qualidade da merenda escolar é grande. Desse modo, $75 \%$ dos diretores consideram adequada a frequência com que realizam essa atividade e os outros $25 \%$ a pontuam como excessiva.

Os resultados contidos nesse quadro demonstram que a maior parte das atividades elencadas são realizadas frequentemente pela maioria dos diretores e que, por essa razão, a maioria considera essa frequência adequada; apenas alguns a veem como excessiva. A única exceção observada é relativa à frequência com que os diretores realizam investimentos no acervo da biblioteca escolar, que se revelou bem baixa.

No terceiro quadro de perguntas foi solicitado que os diretores respondessem sobre a organização da sala e as produções dos alunos. 
Quadro 3 - Organização da sala e produção dos alunos

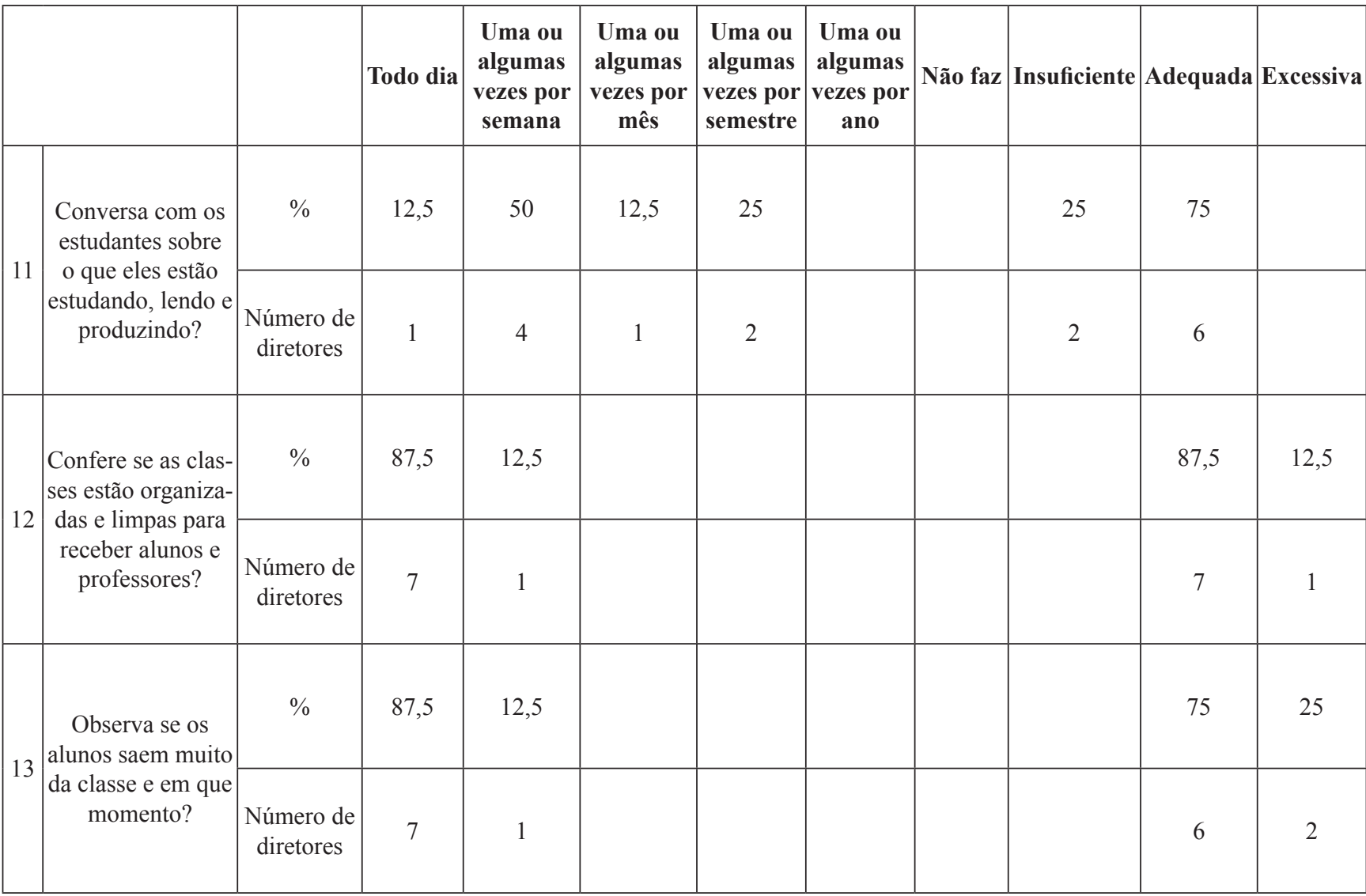

Fonte: Pesquisa de campo.

Ao serem questionados sobre a frequência com que conversam com os alunos sobre o que estão estudando, lendo e produzindo, a metade (50\%) dos diretores afirmou que faz isso uma ou algumas vezes por semana, enquanto que $25 \%$ o fazem uma ou algumas vezes por semestre, $12,5 \%$ fazem todo dia e os outros $12,5 \%$ fazem uma ou algumas vezes por mês. Mesmo com essa variação na frequência, 75\% a consideram adequada e $25 \%$ a julgam insuficiente.

Sobre a conferência da organização e limpeza das classes para o recebimento dos alunos e professores, constatou-se que os entrevistados fazem isso frequentemente, sendo que $87,5 \%$ conferem todo dia e $12,5 \%$ conferem uma ou algumas vezes por semana. Diante da alta frequência com que realizam essa atividade, $87,5 \%$ pontuam como adequada essa frequência e $12,5 \%$ a consideram excessiva.

No que se refere à realização da observação se os alunos saem muito da classe e em quais momentos, foi possível perceber que $87,5 \%$ dos diretores realizam essa atividade todos os dias e $12,5 \%$ deles o fazem uma ou algumas vezes por semana, demonstrando assim que há uma grande preocupação por parte da direção da escola em verificar o desenvolvimento das aulas. Por essa razão, a maioria dos entrevistados (75\%) considera adequada a frequência dessa atividade e $25 \%$ a classificam como excessiva.

Os resultados obtidos no bloco de questões sobre a organização da sala e a produção dos alunos revelam que a preocupação com a limpeza e a organização das salas e com a movimentação dos alunos fora da sala de aula é constante por parte dos diretores entrevistados. No entanto, o acompanhamento do estudo, da leitura e da produção dos alunos ainda é pequeno por parte dos diretores, demonstrando assim que as atividades relacionadas à gestão pedagógica ainda não estão sendo incorporadas totalmente no cotidiano escolar dos gestores.

No quinto quadro as perguntas versavam sobre as atividades que os diretores realizavam com o propósito de interagir com a comunidade. 
Quadro 4 - Interação com a comunidade

\begin{tabular}{|c|c|c|c|c|c|c|c|c|c|c|c|}
\hline & & & Todo dia & $\begin{array}{c}\text { Uma ou } \\
\text { algumas } \\
\text { vezes por } \\
\text { semana }\end{array}$ & $\begin{array}{c}\text { Uma ou } \\
\text { algumas } \\
\text { vezes por } \\
\text { mês }\end{array}$ & $\begin{array}{c}\text { Uma ou } \\
\text { algumas } \\
\text { vezes por } \\
\text { semestre }\end{array}$ & $\begin{array}{c}\text { Uma ou } \\
\text { algumas } \\
\text { vezes por } \\
\text { ano }\end{array}$ & Não faz & Insuficiente & Adequada & Excessiva \\
\hline \multirow{2}{*}{14} & \multirow{2}{*}{$\begin{array}{l}\text { Tem disponibilida- } \\
\text { de para atender os } \\
\text { pais dos alunos? }\end{array}$} & $\%$ & 75 & 25 & & & & & & 100 & \\
\hline & & $\begin{array}{c}\text { Número de } \\
\text { diretores }\end{array}$ & 6 & 2 & & & & & & 8 & \\
\hline \multirow{2}{*}{15} & \multirow{2}{*}{$\begin{array}{c}\text { Realiza com } \\
\text { regularidade } \\
\text { reuniões de pais } \\
\text { para apresentar a } \\
\text { proposta educativa? }\end{array}$} & $\%$ & 12,5 & & 37,5 & 50 & & & 37,5 & 62,5 & \\
\hline & & $\begin{array}{c}\text { Número de } \\
\text { diretores }\end{array}$ & 1 & & 3 & 4 & & & 3 & 5 & \\
\hline \multirow{2}{*}{16} & \multirow{2}{*}{$\begin{array}{c}\text { Orienta os familiares } \\
\text { no acompa- } \\
\text { nhamento da vida } \\
\text { escolar dos filhos? }\end{array}$} & $\%$ & 25 & 12,5 & 37,5 & 25 & & & 12,5 & 87,5 & \\
\hline & & $\begin{array}{c}\text { Número de } \\
\text { diretores }\end{array}$ & 2 & 1 & 3 & 2 & & & 1 & 7 & \\
\hline \multirow{2}{*}{17} & \multirow{2}{*}{$\begin{array}{c}\text { Promove reuniões } \\
\text { com os funcionários } \\
\text { a fim de garantir um } \\
\text { ambiente organizado } \\
\text { e limpo? }\end{array}$} & $\%$ & 25 & 12,5 & 37,5 & & 25 & & 12,5 & 87,5 & \\
\hline & & \begin{tabular}{|c|} 
Número de \\
diretores
\end{tabular} & 2 & 1 & 3 & & 2 & & 1 & 7 & \\
\hline \multirow{2}{*}{18} & \multirow{2}{*}{$\begin{array}{l}\text { Observa como os } \\
\text { pais e a comunidade } \\
\text { são atendidos pelos } \\
\text { funcionários? }\end{array}$} & $\%$ & 87,5 & & & & & 12,5 & 12,5 & 87,5 & \\
\hline & & $\mid \begin{array}{c}\text { Número de } \\
\text { diretores }\end{array}$ & 7 & & & & & 1 & 1 & 7 & \\
\hline \multirow{2}{*}{19} & \multirow{2}{*}{$\begin{array}{c}\text { Recepciona os } \\
\text { alunos na entrada e } \\
\text { na saída da escola? }\end{array}$} & $\%$ & 37,5 & 50 & & & 12,5 & & 25 & 62,5 & 12,5 \\
\hline & & $\begin{array}{c}\text { Número de } \\
\text { diretores }\end{array}$ & 3 & 4 & & & 1 & & 2 & 5 & 1 \\
\hline
\end{tabular}

Fonte: Pesquisa de campo.

A primeira questão desse bloco de perguntas se refere à disponibilidade dos diretores em atender os pais dos alunos, sendo que $75 \%$ dos entrevistados afirmam ter essa disponibilidade todos os dias e $25 \%$ dizem que estão disponíveis uma ou algumas vezes por semana. Considerando a alta frequência com que essa atividade é realizada, $100 \%$ dos diretores consideraram adequada tal regularidade.

Já em relação à frequência com que são realizadas reuniões com os pais para que a proposta educativa da escola seja apresentada, verificou-se que há uma grande variação na regularidade: $50 \%$ dos diretores realizam uma ou algumas vezes por semestre; 37,5\% realizam uma ou algumas vezes por mês; e $12,5 \%$ realizam todos os dias. Apesar da variação na frequência com que tais reuniões são realizadas, a maioria dos diretores $(62,5 \%)$ considera adequada essa frequência, enquanto que $37,5 \%$ a pontuam como insuficiente.

$\mathrm{Na}$ atividade de orientar os familiares para que acompanhem a vida escolar dos alunos, nota-se também uma grande variação na frequência com que essa atividade é realizada: $37,5 \%$ dos diretores orientam uma ou algumas vezes por mês; $25 \%$ uma ou algumas vezes por semestre; $25 \%$ todos os dias; e $12,5 \%$ uma ou algumas vezes por semana. A maioria dos entrevistados $(87,5 \%)$ considera adequada essa frequência e apenas $12,5 \%$ a julgam insuficiente.

$\mathrm{Na}$ frequência da realização de reuniões com os funcionários com a finalidade de garantir um ambiente limpo e organizado também se dá uma grande variação, sendo que $37,5 \%$ dos diretores realizam uma ou 
algumas vezes por mês; $25 \%$ realizam uma ou algumas vezes por ano; outros $25 \%$ realizam todo dia; e $12,5 \%$ realizam uma ou algumas vezes por semana. No que diz respeito ao modo como essas atividades são realizadas, verificou-se que $87,5 \%$ dos entrevistados consideram adequada a frequência e apenas $12,5 \%$ a pontuam como insuficiente.

$\mathrm{Na}$ observação da forma como os pais e a comunidade são atendidos pelos funcionários notou-se que a maioria $(87,5 \%)$ dos entrevistados faz isso todos os dias e apenas $12,5 \%$ não realizam essa atividade. A maioria dos diretores $(87,5 \%)$ declarou que considera adequada a frequência dessa atividade e $12,5 \%$ a rotulam como insuficiente.

A última questão desse bloco solicitava que os diretores entrevistados informassem a frequência com que costumam recepcionar os alunos quando chegam e saem da escola. A metade dos diretores (50\%) informou que costuma recepcionar os alunos uma ou algumas vezes por semana; $37,5 \%$, por sua vez, costumam recepcionar todos os dias os alunos; e $12,5 \%$ costumam recepcioná-los uma ou algumas vezes por ano. Quanto à maneira como essa atividade é realizada, constatou-se que a maioria $(67,5 \%)$ considera adequada; por outro lado, $25 \%$ consideram insuficiente e 12,5 classificam como excessiva.

Os resultados alcançados através das perguntas desse bloco mostram que apesar de a maioria dos entrevistados julgar que todas as atividades são realizadas de forma adequada, nota-se que algumas atividades não são realizadas frequentemente pela maioria, como, por exemplo, as reuniões com os pais e com os funcionários e a orientação dos familiares para que acompanhem a vida escolar dos filhos.

Os resultados da pesquisa realizada pela Fundação Victor Civita com diretores escolares de algumas capitais do país revelaram que, no dia a dia, os diretores passam muito tempo cuidando de tarefas administrativas e pouco tempo cuidando de questões pedagógicas. Segundo a pesquisa, 90\% verificam a produção da merenda todos os dias. $\mathrm{O}$ mesmo vale para a supervisão dos serviços de limpeza (84\%), o fornecimento de lápis e papel $(63 \%)$ e a conferência das condições das carteiras (58\%). Ainda entre as tarefas que são desempenhadas diariamente, $92 \%$ dos diretores afirmam dedicar tempo para atender pais, $74 \%$ para receber os alunos na porta e $89 \%$ para observar o relacionamento entre os funcionários e a comunidade. Porém 50\% não acompanham as reuniões entre os professores e a coordenação pedagógica.

O questionário aplicado solicitava também que os diretores atribuíssem uma nota de 1 a 10 , sendo que o número um representava menor prioridade e o dez indicava maior prioridade para cada atividade (administrativa e pedagógica) realizada por eles durante a gestão, como se pode verificar pelo quadro seguinte.

Quadro 5 - Índice de prioridade das atividades administrativas e pedagógicas

\begin{tabular}{|c|c|c|c|c|c|c|c|c|c|c|}
\hline & $\begin{array}{c}\text { Menor } \\
\text { Prioridade }\end{array}$ & & & & & & & & $\begin{array}{c}\text { Maior } \\
\text { Prioridade }\end{array}$ \\
\hline $\begin{array}{c}\text { Atividades } \\
\text { administrativas/ } \\
\text { burocráticas }\end{array}$ & 1 & 2 & 3 & 4 & 5 & 6 & 7 & 8 & 9 & 10 \\
\hline $\begin{array}{c}\text { Atividades } \\
\text { pedagógicas de } \\
\text { sala de aula }\end{array}$ & 1 & 2 & 3 & 4 & 5 & 6 & 7 & 8 & 9 & 10 \\
\hline
\end{tabular}

Fonte: Pesquisa de campo.

A maioria dos entrevistados $(87,5 \%)$ considerou que as atividades pedagógicas de sala de aula realizadas durante a gestão representam sua maior prioridade, ou seja, atribuiu nota 10 , e $12,5 \%$ dos entrevistados atribuíram a nota 9 para essas atividades. Entretanto, as atividades administrativas/ burocráticas ainda demonstram um alto índice de prioridade, sendo que $62,5 \%$ dos entrevistados atribuíram a elas nota $10 ; 25 \%$ atribuíram nota 7 ; e 12,5 atribuíram nota 9. Conclui-se assim que a maior parte dos diretores entrevistados julga que a realização das duas atividades é fundamental para uma boa gestão escolar.

A última pergunta do questionário solicitava que os diretores apontassem quem seriam, na opinião deles, os três principais responsáveis pela aprendizagem dos alunos dentre seis agentes elencados, como se pode observar no quadro a seguir. 
Quadro 6 - Agentes responsáveis pela aprendizagem

\begin{tabular}{|c|c|c|c|}
\hline & Agentes & Porcentagem & Total de diretores \\
\hline 1 & O professor & $75,00 \%$ & 6 \\
\hline 2 & A direção & $0,00 \%$ & 0 \\
\hline 3 & A coordenação pedagógica da escola & $37,50 \%$ & 3 \\
\hline 4 & A família & $37,50 \%$ & 3 \\
\hline 5 & O governo & $0,00 \%$ & 0 \\
\hline 6 & Os alunos & $62,50 \%$ & 5 \\
\hline
\end{tabular}

Fonte: pesquisa de campo.

Na pesquisa realizada pela Fundação Victor Civita, quando questionados sobre quem seriam os três agentes mais responsáveis pela aprendizagem dos alunos, os diretores entrevistados responderam que o agente mais responsável é o professor (87\%), em segundo lugar a família (65\%) e em terceiro lugar os alunos (57\%). A direção da escola ficou, apenas, em quinto lugar (31\%), atrás da coordenação pedagógica $(38 \%)$ e o governo ficou em sexto lugar $(23 \%)$.

$\mathrm{Na}$ pesquisa com os diretores do município de Reserva a resposta a essa questão não foi muito diferente, como se pode observar no gráfico abaixo.

Gráfico 1 - Principais agentes responsáveis pela aprendizagem

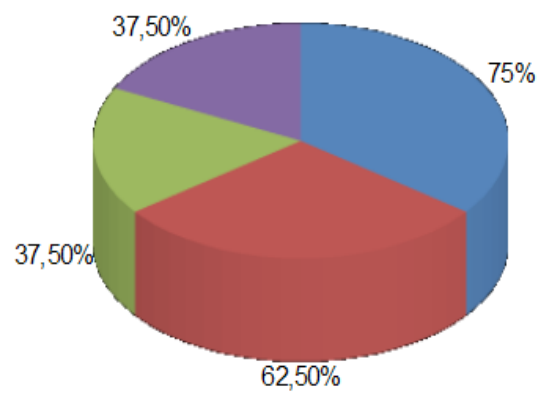

Fonte: Pesquisa de campo

Conforme o Gráfico 1, observa-se que assim como na pesquisa realizada pela Fundação Victor Civita, o principal responsável pela aprendizagem apontado pelos diretores entrevistados é o professor, apenas o percentual (75\%) foi um pouco inferior. Em segundo lugar o resultado foi diferente: os diretores de Reserva consideram os alunos como responsáveis pela aprendizagem; na pesquisa da Fundação é a família. Já em terceiro lugar houve um empate entre a família e a coordenação pedagógica.

Cumpre ressaltar que a direção da escola não foi apontada por nenhum dos entrevistados como um dos três principais responsáveis pela aprendizagem, dado esse que revela que os diretores do município de Reserva não se sentem diretamente responsáveis pelo aprendizado escolar. Isso significa também que ao apontar a coordenação pedagógica como um dos três principais agentes responsáveis pela aprendizagem, os diretores entrevistados demonstram que ainda consideram a equipe pedagógica como mais responsável pela parte pedagógica do que os diretores. Ou seja, apesar de ser função do diretor escolar se preocupar com a gestão pedagógica, considerando que esse é um dos aspectos mais relevantes da gestão escolar, essa noção ainda não está incorporada na visão dos diretores pesquisados.

\section{Considerações finais}

Os resultados da pesquisa realizada com os diretores escolares do município de Reserva evidenciaram que esses profissionais, dentro do exercício de suas funções como gestores, realizam tarefas de cunho administrativo de modo mais frequente, como, por exemplo, no que se refere ao atendimento de aspectos ligados à gestão administrativa e à gestão de recursos humanos.

No que diz respeito à gestão pedagógica, os resultados mostraram que em determinadas tarefas existe uma grande preocupação, especialmente com o fornecimento de materiais pedagógicos, bem como os diretores questionados procuram assegurar um ambiente limpo, organizado, isto é, favorável à prática pedagógica. No entanto, em relação ao atendimento e à orientação sobre a prática pedagógica, os resultados revelaram que ainda é necessário aumentar a frequência com que os diretores realizam tais atividades.

É evidente também que os diretores pesquisados não se consideram como um dos principais 
agentes responsáveis pela aprendizagem dos alunos na escola, apesar de afirmarem que as atividades de cunho pedagógico são prioridade dentro da sua gestão. Isso significa que uma gestão escolar focada na aprendizagem dos alunos ainda não ocorre de forma plena dentro do cotidiano escolar, ou seja, a gestão escolar ainda apresenta muitas limitações no que se refere a sua efetivação. Esperamos, contudo, que os questionamentos e resultados apresentados por esta pesquisa possam contribuir para que haja uma maior reflexão acerca da importância do papel do gestor para o bom desenvolvimento das atividades escolares.

\section{Referências}

ALONSO, Myrtes. Gestão escolar: revendo conceitos. São Paulo: PUC-SP, 2004.

ANTUNES, Rosmeiri Trombini. O gestor escolar. Maringá: SEED, 2008.

FERREIRA, Naura Syria Carapeto.(Org.). Gestão da educação: impasses, perspectivas e compromissos. São Paulo: Cortez, 2006.

LIBÂNEO, José Carlos. Organização e gestão da escola: teoria e prática. 5. ed. Goiânia: Alternativa, 2004.

LIBÂNEO, José Carlos; OLIVEIRA, João Ferreira de; TOSCHI, Mirza Seabra. Educação escolar: políticas, estrutura e organização. São Paulo: Cortez, 2003.

Lima, MC. Monografia: a engenharia da produção acadêmica. São Paulo: Saraiva; 2004.

NASCIMENTO, André Luiz Brito. Gestão da escola pública brasileira: desafios contemporâneos. In: Revista da FACED. Universidade Federal da Bahia, n.09, 2005. p. 157-170.

OLIVEIRA, João Ferreira de; MORAES, Karine Nunes de; DOURADO, Luiz Fernandes. Gestão escolar democrática: definições, princípios, mecanismos de sua implementação. Disponível em: <http://moodle3.mec.gov.br/ufsc/file.php/1/ gestores/politica/pdf/texto2_1.pdf $>$. Acesso em: 31 jan. 2010.

ORDIGNON, Genuíno; GRACINDO, Regina Vinhaes. Gestão da educação: o município e a escola. In: FERREIRA, Naura Syria Carapeto; AGUIAR, Márcia Ângela da Silva. Gestão da Educação: impasses, perspectivas e compromissos. São Paulo: Cortez, 2004.

SILVA, Eliene Pereira da. A importância do gestor educacional na instituição escolar. In: Revista Conteúdo, Capivari, v.1, n.2, jul./dez. 2009 - ISSN 1807-9539, p. 67-83.
TERRIBILI, Armando. Introdução às abordagens quantitativas. In: MACHADO, Lourdes Marcelino; MAIA, Graziela Zambão Abdian; LABEGALINI, Andréia Cristina Fregate Baraldi (org.). Pesquisa em educação: passo a passo. Marília: Edições M3T Tecnologia e Educação, 2007, p. $59-73$.

Data de submissão: 27/09/2012

Data de aceite: $24 / 11 / 2012$ 